\title{
STRATEGI PEMASARAN KOPI SPECTRUM DI KOTA BOGOR
}

\author{
Puji Nurul Hikmah1), dan Wahyu Budi Priatna2) \\ 1)Program Sarjana Agribisnis, Fakultas Ekonomi dan Manajemen Institut Pertanian Bogor \\ 2)Departemen Agribisnis, Fakultas Ekonomi dan Manajemen, Institut Pertanian Bogor \\ Jl. Kamper Wing 4 Level 5 Kampus IPB Dramaga, Indonesia \\ 1)e-mail: pujinurul21@gmail.com
}

(Diterima 7 Juli 2020 / Disetujui 29 Juli 2020)

\begin{abstract}
The gaining of society's enthusiasm for coffee can be seen from the increased number of coffee consumption in Indonesia. This would be an opportunity for an entrepreneur to open a coffee shop. The number of coffee shops has always increased from year to year, especially in Bogor City as one of the tourism cities in Indonesia. In this situation, the level of competition will surely increase. Therefore, effective alternative strategies are needed to succeed in this competition. The purpose of this research is to identify the internal and external environmental factors of the company to formulate the priorities of the right marketing strategies. The methods used in this research are the IFE matrix, EFE matrix, IE matrix, SWOT matrix, and QSPM (Quantitative Strategic Planning Matrix). The result of the analysis shows that Kopi Spectrum is in a position of growth and build. Five marketing strategies generated from SWOT Matrix Analysis, that can be implemented by Kopi Spectrum, maintain product quality with an appropriate price (SO1), improve promotional activities that are suitable for the targets (W01), expand a network of suppliers (ST1), maintain the number of consumers they already have with services and facilities (ST2), and get the halal certificate (WT1). Based on QSPM calculations, the priority strategy from Kopi Spectrum is to maintain the number of consumers they already have with services and facilities.
\end{abstract}

Keywords: coffee shop, IFE EFE, IE, SWOT, QSPM

\begin{abstract}
ABSTRAK
Animo masyarakat akan kopi yang meningkat dapat dilihat dari adanya peningkatan angka konsumsi kopi di Indonesia. Hal tersebut merupakan sebuah peluang bagi seorang pengusaha untuk membuka coffee shop. Jumlah coffee shop selalu mengalami peningkatan dari tahun ke tahun terutama di Kota Bogor sebagai salah satu kota wisata. Seiring dengan peningkatan tersebut, tingkat persaingan pun semakin bertambah. Oleh sebab itu, alternatif strategi yang efektif sangat diperlukan agar dapat berhasil dalam persaingan. Tujuan penelitian ini adalah untuk mengidentifikasi faktor lingkungan internal dan eksternal perusahaan sehingga diperoleh rumusan prioritas alternatif strategi pemasaran yang tepat. Metode yang digunakan dalam penelitian ini adalah matriks IFE, matriks EFE, matriks IE, matriks SWOT, dan QSPM (Quantitative Strategic Planning Matrix). Hasil analisis menunjukkan bahwa Kopi Spectrum berada pada posisi tumbuh dan membangun. Analisis Matriks SWOT menghasilkan lima alternatif strategi pemasaran yang dapat diterapkan oleh Kopi Spectrum yaitu mempertahankan kualitas produk dengan harga yang sesuai (SO1), meningkatkan kegiatan promosi sesuai dengan target sasaran (WO1), memperluas jaringan pemasok (ST1), mempertahankan konsumen yang sudah ada dengan pelayanan dan kelengkapan fasilitas (ST2), dan memperoleh sertifikat halal (WT1). Berdasarkan perhitungan QSPM, prioritas strategi dari Kopi Spectrum adalah mempertahankan konsumen yang sudah ada dengan pelayanan dan kelengkapan fasilitas.
\end{abstract}

Kata kunci: IFE, EFE, IE, kedai kopi, SWOT, QSPM

\section{PENDAHULUAN}

Kopi Spectrum berada di Jalan Jalak Harupat No 19, Babakan, Bogor Tengah. Terdapat beberapa coffee shop sejenis di Kota Bogor yang menyebabkan angka persaingan meningkat. Jum- lah konsumen Kopi Spectrum mengalami fluktuasi. Oleh sebab itu, manajemen dari Kopi Spectrum harus bisa merumuskan beberapa strategi pemasaran yang efektif dan tepat agar bisa menarik konsumen lebih banyak hingga konsumen tersebut berada di tingkat loyalitas 
sehingga dapat melakukan pembelian ulang. Selama tahun 2018, Kopi Spectrum mengalami fluktuasi jumlah konsumen yang disajikan pada grafik berikut ini.

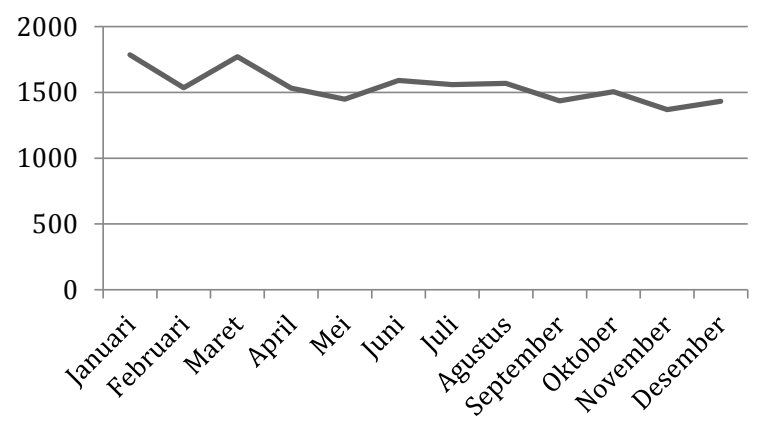

Gambar 1. Jumlah Konsumen Kopi Spectrum 2018

Sumber : Kopi Spectrum (Diolah 2019)

Peningkatan maupun penurunan jumlah konsumen tidak terlalu signifikan, namun cenderung memperlihatkan penurunan pada semester akhir. Target pasar yang ditetapkan oleh Kopi Spectrum juga jarang terpenuhi perharinya. Dalam hari kerja terlihat konsumen sangat jarang, namun begitu hari libur banyak konsumen yang datang. Hal ini menunjukkan bahwa terjadi ketimpangan jumlah konsumen yang signifikan antara hari kerja dan hari libur.

Dalam menjalankan usahanya, sangat diperlukan strategi pemasaran yang tepat dan efektif yang akan membuat penjualan Kopi Spectrum mengalami peningkatan. Untuk dapat mencapai tujuan perusahaan, Kopi Spectrum perlu merumuskan beberapa strategi yang tepat dan efektif. Berdasarkan uraian yang disampaikan diatas, dapat dirumuskan berbagai permasalahan yang akan diteliti.

1. Apa saja faktor-faktor strategis lingkungan internal maupun eksternal yang memengaruhi keberhasilan usaha Kopi Spectrum?

2. Bagaimana alternatif strategi pemasaran yang dapat diterapkan di Kopi Spectrum?

3. Bagaimana prioritas alternatif strategi pemasaran yang sebaiknya diterapkan oleh Kopi Spectrum?

Berdasarkan perumusan masalah yang akan diteliti, maka tujuan dari penelitian ini adalah sebagai berikut
1. Mengidentifikasi faktor-faktor strategis lingkungan internal maupun eksternal yang memengaruhi keberhasilan usaha Kopi Spectrum.

2. Menyusun alternatif strategi pemasaran yang dapat diterapkan di Kopi Spectrum.

3. Menganalisis prioritas alternatif strategi pemasaran yang sebaiknya diterapkan oleh Kopi Spectrum.

Penelitian ini difokuskan pada identifikasi kegiatan pemasaran yang telah dilakukan oleh perusahaan, perumusan alternatif strategi, dan penentuan prioritas strategi pemasaran berdasarkan analisis kondisi lingkungan internal maupun eksternal perusahaan yang akan menghasilkan aspek kekuatan, kelemahan, peluang, dan ancaman bagi perusahaan.

\section{METODE}

\section{LOKASI DAN WAKTU PENELITIAN}

Penelitian dilakukan di Kopi Spectrum yang beralamatkan di Jalan Jalak Harupat No 19, Babakan, Bogor Tengah, Kota Bogor. Kopi Spectrum merupakan salah satu kedai kopi (coffee shop) yang tergolong baru dan membutuhkan strategi pemasaran yang tepat agar dapat bersaing dengan coffee shop lainnya, ini yang menjadi alasan pemilihan lokasi yang dilakukan dengan sengaja (purposive sampling). Kegiatan penelitian untuk pengambilan dan pengolahan data dilakukan pada Desember 2018 - Januari 2019.

\section{JENIS DAN SUMBER DATA}

Jenis data yang dikumpulkan adalah data primer dan data sekunder yang bersifat kualitatif maupun kuantitatif. Data primer diperoleh dengan melakukan observasi langsung dan wawancara dengan responden yang memahami bagaimana strategi pemasaran pada Kopi Spectrum yaitu CEO, Administrator, dan Head Barista. Data sekunder merupakan data yang diambil dari studi pustaka atau pencairan literatur-literatur seperti laporan internal perusahaan, baik bulanan maupun tahunan, penelitian terdahulu, situs internet, dan jurnal yang relevan dengan penelitian ini sebagai pelengkap data primer dan mendukung penelitian. 


\section{METODE PENGAMBILAN DATA}

Metode pengumpulan data baik primer maupun sekunder untuk penelitian ini adalah sebagai berikut:

1. Teknik studi kepustakaan : membaca penelitian terdahulu yang relevan dengan penelitian seperti skripsi dan tesis, jurnal, buku, serta artikel yang menunjang penelitian.

2. Studi Pendahuluan : pengumpulan data dengan mendatangi Kopi Spectrum guna melakukan observasi langsung dan wawancara dengan CEO sebelum memulai penelitian guna memperoleh gambaran mengenai perusahaan.

3. Teknik Wawancara : responden dipilih dengan teknik sampling tertentu didasarkan pada pihak yang berperan dan memahami strategi perusahaan.

4. Teknik Kuisioner : daftar pertanyaan yang sebelumnya telah disusun diajukan kepada para responden.

\section{METODE PENENTUAN RESPONDEN}

Terdapat dua jenis responden dalam penelitian ini yaitu responden dari internal dan responden dari eksternal Kopi Spectrum. Responden internal merupakan pihak manajeman Kopi Spectrum. Responden internal dipilih dengan metode judgement sampling. Responden yang dipilih berjumlah empat orang yaitu CEO, Administrator (berjumlah dua orang), dan Head Barista. Pemilihan responden berdasarkan beberapa pertimbangan bahwa pihak tersebut mempunyai informasi yang dibutuhkan untuk penelitian serta memiliki pengalaman, keahlian, dan pengetahuan dalam menangani permasalahan di Kopi Spectrum terutama pada aspek strategi pemasaran

Responden eksternal dipilih dengan teknik convenience sampling. Terpilihlah sebanyak 30 orang konsumen Kopi Spectrum sebagai responden penelitian. Pengambilan data dilakukan dengan wawancara langsung maupun kuisioner online. Informasi yang diperoleh dari para konsumen ini berfungsi untuk menguatkan dan mendukung pernyataan dari responden pihak internal Kopi Spectrum sehingga data yang didapat dapat diolah dengan baik.

\section{METODE PENGOLAHAN DAN ANALISIS DATA}

Dalam penelitian ini, penulis menggunakan analisis kualitatif dan analisis kuantitatif. Analisis kualitatif mencakup analisis kekuatan dan kelemahan internal perusahaan dan analisis peluang dan ancaman eksternal perusahaan. Sementara itu, analisis kuantitatif mencakup perumusan matriks IFE EFE, matriks IE, matriks SWOT, dan QSPM. Keduanya digunakan untuk penentuan alternatif strategi terbaik. Menurut David (2009), analisis strategi pemasaran mencakup tiga tahap formulasi strategi yaitu input stage, matching stage, dan decision stage.

Input stage merupakan tahap awal formulasi strategi yang meliputi identifikasi faktor internal dan eksternal perusahaan guna menganalisis kekuatan dan kelemahan perusahaan serta peluang dan ancaman bagi perusahaan, pemberian bobot faktor, rating, dan perkalian antar keduanya oleh masing-masing responden. Tahap ini dianalisis dengan menggunakann matriks IFE dan matriks EFE.

Tahap selanjutnya yaitu matching stage. Tahap ini berfokus pada identifikasi alternatif strategi dengan memperhatikan faktor-faktor internal dan eksternal perusahaan dengan mencocokkan informasi pada tahap masukan (input stage). Alat analisis yang digunakan pada tahap ini adalah matriks IE (Internal-Eksternal) untuk mengetahui posisi Kopi Spectrum dan matriks SWOT (Strength, Weakness, Opportunity, dan Threat) untuk merumuskan alternatif strategi yang dapat diterapkan oleh Kopi Spectrum.

Tahap terakhir adalah decision stage. Pada tahap keputusan ini menggunakan QSPM (Quantitative Strategic Planning Matrix) untuk menyusun alternatif strategi secara objektif berdasarkan hasil analisis matriks SWOT yang sebelumnya telah diidentifikasi terlebih dahulu. QSPM akan menunjukkan prioritas strategi yang dapat diterapkan pada Kopi Spectrum.

\section{GAMBARAN UMUM}

Kopi Spectrum adalah salah satu coffee shop yang menyajikan minuman specialty coffee yang beralamatkan di Jalan Jalak Harupat No 19, Babakan, Bogor Tengah, Kota Bogor . Istilah specialty coffee diciptakan oleh Erna Knutsen di Tea \& Coffee Trade Journal pada tahun 1974. Arti 
dari specialty coffee itu sendiri adalah kopi dengan kualitas tertinggi yang diolah khusus dengan prosedur khusus dari proses awal pengolahan biji kopi hingga tersaji dalam cangkir.

Kopi Spectrum yang didirikan oleh Bapak Tresna Yaniza Putra telah berdiri sejak 27 Desember 2017 dengan nama "Kopi Boutique", namun pada bulan Mei 2018 berganti nama menjadi "Kopi Spectrum". Nama Spectrum terinspirasi karena Indonesia sendiri merupakan penghasil jenis kopi dengan varian yang bermacam-macam sehingga membentuk spectrum rasa yang khas.

\section{VISI DAN MISI}

Visi dari Kopi Spectrum ini adalah untuk mendapatkan insentif keuntungan, membuka lapangan pekerjaan, dan untuk memperkenalkan kopi kepada masyarakat Bogor, sedangkan untuk misinya yaitu menjual berbagai minuman olahan kopi dengan membuka coffee shop.

\section{HASIL DAN PEMBAHASAN}

\section{INPUT STAGE (IDENTIFIKASI FAKTOR INTERNAL DAN EKSTERNAL)}

Pada tahap ini dilakukan analisis lingkungan usaha yang terdiri dari lingkungan internal dan eksternal.

\section{Faktor Internal}

Aspek yang dianalisis dalam lingkungan internal yaitu aspek bauran pemasaran 7P (product, price, place, promotion, physical evidence, process, people). Berdasarkan hasil analisis lingkungan internal dapat disimpulkan, bahwa kekuatan yang dimiliki oleh Kopi Spectrum adalah sebagai berikut :

1. Menu yang bervariasi

Selain minuman olahan kopi, Kopi Spectrum juga menyediakan menu minuman non kopi dan makanan. Minuman non kopi yang tersedia adalah olahan teh, cokelat, dan susu. Makanan yang tersedia adalah berupa salad, pizza, sandwich, nasi goreng, mi goreng, bubur, pasta, dessert, dll.

2. Kopi yang disajikan adalah specialty coffee Specialty coffee merupakan grade unggul dengan nilai 80 - 100 di mana tidak semua coffee shop mensuplai biji kopi jenis ini karena biaya yang lebih mahal dibandingkan biji kopi biasa.

3. Parkiran luas

Kondisi lahan parkir yang dapat memuat hingga tigabelas buah mobil dan empat puluh sepeda motor.

4. Fasilitas lengkap (wifi, ruangan ber-AC, musala, toilet, alunan musik)

Lengkapnya fasilitas yang tersedia di Kopi Spectrum membuat konsumen yang datang merasa nyaman dan betah saat berkunjung.

5. Ruangan khusus (smoking, non-smoking, coworking space dan meeting room)

Kopi Spectrum menyediakan dua jenis ruangan yaitu smoking dan non-smoking. Terdapat juga fasilitas co-working space dan meeting room yang dapat disewa untuk kepentingan rapat atau diskusi yang nyaman

6. Kesesuaian citarasa dengan harga produk Kopi Spectrum senantiasa menjada kualitas citarasa produknya agar konsumenya merasa puas dengan harga yang harus mereka bayar.

7. Lokasi yang strategis Berada di Jalan Jalak Harupat No 19 pada ring satu daerah Kebun Raya Bogor membuat Kopi Spectrum menjadi strategis dalam hal geografis.

8. Produk berkualitas

Kopi Spectrum menggunakan bahan baku kopi dan non kopi yang berkualitas sangat baik. Proses pengolahannya pun telah memiliki standar tersendiri.

9. Kualitas pelayanan yang baik

Produk yang baik jika tidak diimbangi dengan pelayanan yang baik tentu akan timpang. Dalam melayani para konsumennya, karyawan Kopi Spectrum memiliki SOP tersendiri yaitu selalu tersenyum kepada konsumen, bersikap ramah, rapi, good attitude, cekatan dalam menyajikan dan mengantar produk, dan selalu mengucapkan terima kasih kepada para konsumen.

10. Kebersihan dan kenyamanan kafe Para karyawan Kopi Spectrum telah menanamkan inisiatif dalam menjaga kebersihan tempat pada budaya kerjanya. Selain itu, Kopi Spectrum telah berlangganan jasa kebersihan online seperti Go-Clean sebanyak dua kali dalam sebulan. 
11. Tempat luas dengan kapasitas pengunjung hingga 100 orang

Bangunan Kopi Spectrum memiliki luas bangunan $600 \mathrm{~m}^{2}$. Terdapat kurang lebih 100 kursi dan 20 meja yang tersebar di seluruh ruangan.

Berdasarkan hasil analisis lingkungan internal dapat disimpulkan, bahwa kelemahan yang dimiliki oleh Kopi Spectrum adalah sebagai berikut :

1. Promosi kurang maksimal

Saat ini media promosi online yang digunakan adalah berupa akun official Instagram "kopispectrum" yang baru memiliki 913 pengikut, akun Facebook "Kopi Spectrum”, dan Google Review. Dibandingkan dengan coffee shop lain, aktifitas media online dan promosi yang dilakukan Kopi Spectrum masih kalah.

2. Belum terdapat plang nama di depan jalan Belum adanya plang nama membuat beberapa konsumen baru, yaitu konsumen yang sebelumnya belum pernah datang ke Kopi Spectrum, selalu berlalu tanpa menyadari keberadaan Kopi Spectrum.

3. Belum memiliki sertifikat halal

Sertifikat halal merupakan spesifikasi yang dikeluarkan oleh LPPOM MUI agar dapat memperoleh kepercayaan atas kehalalan produknya di mata masyarakat muslim.

\section{Faktor Eksternal}

Aspek yang dianalisis pada lingkungan eksternal yaitu lingkungan eksternal makro yang terdiri dari kekuatan ekonomi, kekuatan sosial, budaya, demografi, dan lingkungan, kekuatan politik, pemerintahan, dan hukum, kekuatan teknologi, dan kekuatan kompetitif serta lingkungan eksternal industri yang terdiri dari persaingan dalam perusahaan sejenis, ancaman pendatang baru, ancaman produk substitusi, daya tawar supplier, dan daya tawar pembeli. Berdasarkan hasil analisis lingkungan eksternal dapat disimpulkan, bahwa peluang bagi Kopi Spectrum adalah sebagai berikut :

1. Peningkatan gaya hidup

Peningkatan gaya hidup outgoing lifestyle juga mengubah kebiasaan masyarakat dari hanya minum kopi di rumah menjadi minum kopi di kafe (coffee shop).

2. Perkembangan teknologi

Kopi Spectrum telah memanfaatkan berbagai ternologi dalam pengolahan biji kopi dan peralatan kafe sehingga dapat menjadi lebih mudah serta dapat menekan biaya operasional.

3. Peningkatan daya beli konsumen Daya beli konsumen di Kota Bogor dapat dikategorikan tinggi. Pernyataan tersebut didukung dengan data PDRB (Produk Domestik Reional Bruto) Kota Bogor (BPS Kota Bogor 2019) yang menunjukkan tahun 2013 hingga 2017 PDRB per kapita atas dasar harga konstan Kota Bogor terus mengalami peningkatan.

4. Peningkatan jumlah wisatawan di Kota Bogor Saat akhir pekan, banyak pendatang dari luar kota. Terlebih di Kebun Raya Bogor yang lokasinya berdekatan dengan lokasi Kopi Spectrum

5. Tingkat kesejahteraan masyarakat Kota Bogor Tingkat kesejahteraan masyarakat Kota Bogor yang tinggi diharapkan dapat menjadi sebuah peluang untuk melakukan pembelian di Kopi Spectrum.

6. Animo masyarakat akan kopi meningkat Kesadaran akan manfaat akan kopi serta perubahan gaya hidup menyebabkan angka konsumsi kopi di Indonesia mengalami peningkatan.

Berdasarkan hasil analisis lingkungan eksternal dapat disimpulkan, bahwa ancaman bagi Kopi Spectrum adalah sebagai berikut :

1. Jumlah coffee shop meningkat

Seiring dengan peningkatan angka konsumsi kopi di Indonesia, menyebabkan jumlah coffee shop (kedai kopi) mengalami peningkatan yang signifikan. Hal itu dapat meningkatkan angka persaingan.

2. Bahan baku yang tidak bermutu yang disebabkan oleh perubahan iklim

Bahan baku biji kopi di suplai langsung dari petani kopi. Salah satu faktor yang mempengaruhi hasil panen adalah iklim. Jika iklim tidak mendukung, maka dikhawatirkan hasil panen yang di dapat tidak sesuai target 
sehingga akan berimbas kepada pemenuhan bahan baku Kopi Spectrum yang tidak maksimal

3. Kekuatan tawar-menawar konsumen Untuk coffee shop lokal seperti Kopi Spectrum acap kali dicap konsumen menawarkan harga yang lebih mahal, padahal jika dibandingkan dengan coffee shop internasional seperti Starbucks maupun yang lainnya, konsumen rela membayar dengan harga yang lebih mahal tanpa mengeluh atau komplain. Posisi bargaining position konsumen di sini tinggi sehingga bisa saja menimbulkan penurunan harga jika dirasa perlu.

\section{MATCHING STAGE (ALTERNATIF STRATEGI PEMASARAN)}

Pada tahap ini, pembuat strategi berfokus pada identifikasi alternatif strategi dengan memperhatikan faktor-faktor internal dan eksternal perusahaan dengan mencocokkan informasi pada tahap masukan. Alat analisis yang digunakan pada tahap ini adalah matriks IE dan matriks SWOT.

Hasil analisis menggunakan matriks IE, diperoleh bahwa posisi Kopi Spectrum berada pada sel IV yang artinya tumbuh dan membangun. Di mana di posisi tersebut faktor internalnya lebih kuat daripada faktor eksternalnya. Hasil matriks SWOT, diperoleh lima alternatif strategi yaitu :

1. Mempertahankan kualitas produk dengan harga yang sesuai

2. Meningkatkan kegiatan promosi sesuai dengan target sasaran

3. Memperluas jaringan pemasok

4. Mempertahankan konsumen yang sudah ada dengan pelayanan dan kelengkapan fasilitas

5. Memperoleh sertifikat halal

\section{DECISION STAGE (PRIORITAS STRATEGI)}

Hasil analisis QSPM yang merupakan prioritas strategi Kopi Spectrum berdasarkan urutan peringkat STAS adalah sebagai berikut:

a. Mempertahankan konsumen yang sudah ada dengan pelayanan dan kelengkapan fasilitas (ST2) dengan nilai STAS sebesar 6,78

b. Meningkatkan kegiatan promosi sesuai dengan target sasaran (W01) dengan nilai STAS sebesar 6,69 c. Memperluas jaringan pemasok (ST1) dengan nilai STAS sebesar 6,58

d. Memperoleh sertifikat halal (WT1) dengan nilai STAS sebesar 6,48

e. Mempertahankan kualitas produk dengan harga yang sesuai (SO1) dengan nilai STAS sebesar 6,29

Dapat disimpulkan bahwa yang menjadi prioritas strategi adalah mempertahankan konsumen yang sudah ada dengan pelayanan dan kelengkapan fasilitas

\section{SIMPULAN DAN SARAN}

\section{SIMPULAN}

1. Faktor strategis internal terdiri dari sebelas aspek kekuatan yaitu berupa (1) menu yang bervariasi; (2) kopi yang disajikan adalah specialty coffee; (3) parkiran luas; (4) fasilitas lengkap (wi-fi, ruangan ber-AC, musholla, toilet, dan alunan music); (5) tersedia ruangan khusus (smoking, non-smoking, co-working space, dan meeting room); (6) kesesuaian citarasa dengan harga produk; (7) lokasi yang strategis; (8) produk berkualitas; (9) kualitas pelayanan yang baik; (10) kebersihan dan kenyamanan kafe; (11) tempat luas dengan kapasitas pengunjung hingga 100 orang dan tiga aspek kelemahan yaitu berupa (1) promosi kurang maksimal; (2) belum terdapat papan nama (plang) di depan jalan; (3) belum memiliki sertifikat halal. Faktor strategis eksternal terdiri dari enam aspek peluang yaitu berupa (1) perubahan gaya hidup; (2) perkembangan teknologi; (3) peningkatan daya beli konsumen; (4) peningkatan jumlah wisatawan di Kota Bogor; (5) tingkat kesejahteraan masyarakat Kota Bogor cukup tinggi; (6) animo masyarakat akan kopi meningkat dan tiga aspek ancaman yaitu berupa (1) jumlah coffee shop meningkat; (2) Bahan baku yang tidak bermutu yang disebabkan oleh perubahan iklim; (3) kekuatan tawar-menawar konsumen.

2. Hasil analisis matriks SWOT menghasilkan lima alternatif strategi yaitu mempertahankan kualitas produk dengan harga yang sesuai (SO1); (2) meningkatkan kegiatan promosi sesuai dengan target 
sasaran (W01); (3) memperluas jaringan pemasok (ST1); (4) mempertahankan konsumen yang sudah ada dengan pelayanan dan kelengkapan fasilitas (ST2); (5) memperoleh sertifikat halal (WT1).

3. Hasil analisis QSPM menunjukkan bahwa strategi yang menjadi prioritas bagi Kopi Spectrum adalah mempertahankan konsumen yang sudah ada dengan pelayanan dan kelengkapan fasilitas dengan nilai STAS sebesar 6,78.

\section{SARAN}

Berdasarkan hasil penelitian berupa analisis faktor lingkungan internal maupun eksternal yang dilakukan di Kopi Spectrum, ada beberapa saran yang dapat dipertimbangkan oleh pihak internal Kopi Spectrum. Pertama, Kopi Spectrum diharapkan untuk lebih agresif lagi dalam melakukan upaya promosi seperti melakukan upaya promo dan memperbanyak aktivitas di media online. Kedua, Kopi Spectrum dianjurkan segera membuat plang di depan jalan untuk mempermudah konsumen menemukan lokasi Kopi Spectrum. Ketiga, Kopi Spectrum diharapkan segera mengurus berkas-berkas ke lembaga atau badan yang berwenang agar dapat memperoleh sertifikat halal MUI.

\section{DAFTAR PUSTAKA}

[BPS] Badan Pusat Statistik. 2019. PDRB Per Kapita Atas Dasar Harga Konstan (Juta Rupiah) Tahun 2013-2017. Badan Pusat Statistik. Bogor.

[Dispenda] Dinas Pendapatan Daerah Kota Bogor. 2018. Perkembangan Jumlah Coffee Shop di Kota Bogor Tahun 2013 - 2017. Dinas Pendapatan Daerah Kota Bogor. Bogor.

David FR. 2009. Manajemen Strategis : Konsep. Edisi 12. Sunardi D, penerjemah; Wuriarti P, editor. Salemba Empat. Jakarta.

International Coffee Organization (ICO). 2018. Konsumsi Kopi di Indonesia. https://www.ico.org/. Diakses 15 Desember 2018.
Kopi Spectrum. 2018. Laporan Penjualan 2018. Kopi Spectrum. Bogor.

Tjiptono F. 2008. Strategi Pemasaran. Edisi 3. CV. Andi Offset. Yogyakarta 